Chapman University

Chapman University Digital Commons

Marriage and Family Therapy Faculty Articles and Research

10-15-2019

\title{
The Complex Relationship Between Celebrity-Driven Magazines and Depictions of Fertility at Advanced Reproductive Ages
}

Brennan Peterson

Follow this and additional works at: https://digitalcommons.chapman.edu/mft_articles

Part of the Communication Technology and New Media Commons, Critical and Cultural Studies Commons, Marriage and Family Therapy and Counseling Commons, Mass Communication Commons, Other Communication Commons, Other Psychiatry and Psychology Commons, Reproductive and Urinary Physiology Commons, and the Women's Health Commons 
The Complex Relationship Between Celebrity-Driven Magazines and Depictions of Fertility at Advanced Reproductive Ages

Brennan Peterson, Ph.D.

Professor, Chapman University, Crean College of Health and Behavioral Sciences, Marriage and Family Therapy Program, Orange CA 92866

bpeterson@chapman.edu

Acknowledgments: The author wishes to thank Ross Crothers, Jean Marie Place, Brooke Edge, and Cassidy Manton for their contributions to this editorial. 
In this issue of the Journal of Women's Health, Willson and colleagues explore how age and fertility are portrayed in celebrity-driven magazines. ${ }^{1}$ Specifically, they examine if popular media depictions of celebrity pregnancies present accurate information related to age and fertility, the use of assisted reproductive technology (ARTs), and pregnancy-related risks associated with advanced maternal age ( $A M A \geq 35$ years). Their study provides an important viewpoint related to the impact of media on reproductive perceptions, and its potential intersection with delayed childbearing, fertility awareness, and reproductive decision making.

The relationship between age and fertility is widely misunderstood. Over the past twentyfive years, seventy-one studies from twenty-six countries have found that women and men consistently lack a proper understanding of the impact of age on fertility, as well as the likelihood of pregnancy at later ages. ${ }^{2}$ These findings are not limited to the general population, but have been repeatedly found in undergraduate and graduate university students. ${ }^{3}$ Amazingly it has even been found in OB/GYN residents, ${ }^{4}$ and practicing health care professionals. ${ }^{5}$ For those who intend to become parents, poor fertility awareness is problematic as it can lead to uninformed decision-making which can ultimately result in involuntary childlessness.

Willson and colleagues also argue that misleading depictions of fertility and age might negatively impact readers' attitudes towards ARTs. Similar to misperceptions about age and fertility, studies consistently find that women and men overestimate the success rates of ARTs especially for women of AMA. ${ }^{2}$ While the total percentage of women using ARTs is unknown, in 2014 nearly 64,000 thousand children were born in the U.S. who were conceived through ARTs. $^{6,7}$ Of the 240 celebrities profiled, only three indicated the use of ARTs. Given that $56 \%$ of celebrities were of AMA, it is likely that the number using ARTs is higher than the number 
portrayed in the magazines. This is particularly true for women over 40 . Between 1990 and 2013, while the birth rates for women ages 40 to 44 in the United States has nearly doubled, ${ }^{8}$ women in their 40s are more likely to experience infertility, undergo a higher number of ART cycles, yet are less likely to deliver a live birth using ARTs. ${ }^{9}$ The realities of achieving a live birth using ARTs for women over 40 are far less optimistic than most people believe. A study of 909 women undergoing IVF treatments concluded that patients over 40 could only expect a $12 \%$ cumulative delivery rate from their use of ARTs. ${ }^{10}$

Understanding the pregnancy-related risks in women of AMA is also a key component of informed reproductive decision-making. Pregnancy-related risks such as pregnancy loss, trisomy, preterm birth, preeclampsia, and gestational diabetes rise significantly in women 35 years and older. ${ }^{11}$ Willson notes that there were only two mentions of pregnancy related risks in the four years of articles studied - despite the fact that the majority of celebrities portrayed were 35 or older (AMA). This omission furthers the gap between what is portrayed as normal in popular print magazines and what actually occurs. A 2018 study found that a sample of welleducated women who believed they were very aware of the pregnancy related risks associated with AMA were not nearly as informed as they believed they were. ${ }^{12}$ By failing to inform readers of pregnancy-related risks in stories of women of AMA, readers can be left with false impressions about the ease of pregnancy and lack of risks to women of AMA.

But what role, if any, does exposure to celebrity-driven stories in the print media have on readers' fertility attitudes and parenting desires? While studies have found that an individual's fertility desires can change after receiving fertility-related education, ${ }^{13}$ and in response to key life events (age and relationship status), ${ }^{14}$ the impact of media on perceptions 
and attitudes towards fertility desires is less well-understood. Social commentaries warn against the negative implications of misrepresenting female fertility in media, suggesting it may mislead readers to develop incorrect interpretations of female fertility. ${ }^{15}$ Empirical examinations support the idea. A 2016 study of 166 childless women found that exposure to portrayals of women in three different roles (professional, beauty, homemaking) in print magazines changed participants future fertility decisions about the number of children desired and number of years until desired birth. Participants shown women in the homemaking and beauty portrayals increased the number of desired children over time, while women shown the professional portrayals increased the time planned to first birth compared to participants shown the beauty portrayals. ${ }^{16}$

In Willson's study, fertility was highlighted on $1 / 3$ of all magazine covers - with many containing attention-grabbing and potentially misleading headlines. If exposure to depictions of women in a professional or a homemaker role can change fertility intentions, exposure to misleading magazine headlines and stories about pregnancy at later-than-expected ages may impact attitudes as well. Of the magazines studied, Willson verified circulation numbers to be in the millions each year - showing the enormous reach and influence these stories can have in shaping public perceptions.

When considering the implications of Willson's findings, it is important to address the issues of celebrity privacy and the role of popular print media in educating readers with fertility-related facts. Regarding privacy, the intimate details of a person's reproductive journey - whether they are a celebrity or not - is that person's alone to share. As such, celebrity privacy should be fiercely protected - a point Willson and colleagues support. In terms of the role of 
print media, Willson and colleagues propose there is 'an opportunity and possibly even a responsibility for magazines and other media outlets to include facts and statistics alongside the anecdotal stories related to infertility.' This call for educational side-bar discussions about fertility issues alongside stories of celebrity pregnancies represents a promising compromise. Such discussions could protect celebrity privacy while adding important fertility-related information that could help inform readers. While there will never be a perfect fit between the aims of for-profit magazines and fertility educators and health care professionals, an outsidethe-box solution such as this could provide a collaborative starting point that serves both interests.

In summary, the relationship between popular celebrity-driven magazines and representations of age and fertility is complex. Important questions that need further discussion include: 'Do misleading headlines and pregnancy related stories actually shape and alter fertility-related attitudes and desires?’; ‘How can popular print media protect the privacy of celebrity interviews while publishing articles that provide socially responsible and accurate portrayals of fertility and age?'; and 'Is there an ethical responsibility for influential for-profit media outlets to provide accurate information to readers to prevent misinformed perceptions of fertility?' All of these questions do not have easy answers. Yet if common ground can be found in addressing these topics, the aims of print media and fertility educators might come more in harmony with one another. It might be possible for print media to can continue to profile celebrity pregnancies, while also helping readers become more informed about the relationship between age and fertility. By providing more accurate information, readers can develop more realistic views about fertility and be empowered to make more informed 
reproductive decisions. At the same time, they can still find pleasure and entertainment in the celebrity-driven stories they are sure to enjoy. 


\section{References}

1. Willson S, Perelman A, Goldman K. "Age is just a number": How celebrity-driven magazines misrepresent fertility at advanced reproductive ages. J Womens Health 2019;xx:xx-xx.

2. Pedro J, Brandão T, Schmidt L, Costa ME, Martins MV. What do people know about fertility? A systematic review on fertility awareness and its associated factors. Upsala J Med Sci 2018;123:71-81.

3. Peterson BD, Pirritano M, Tucker L, Lampic C. Fertility awareness and parenting attitudes among American male and female undergraduate university students. Hum Reprod 2012;27:1375-1382.

4. Yu L, Peterson B, Inhorn MC, Boehm JK, Patrizio P. Knowledge, attitudes, and intentions toward fertility awareness and oocyte cryopreservation among obstetrics and gynecology resident physicians. Hum Reprod 2016;31:403-411.

5. García D, Vassena R, Prat A, Vernaeve V. Poor knowledge of age-related fertility decline and assisted reproduction among healthcare professionals. Reprod Biomed Online 2017;34:32-37.

6. Hamilton BE, Martin JA, Osterman MJ, Curtin SC, Mathews TJ. Births: Final Data for 2014. Natl Vital Stat Rep 2015;64:1-64.

7. Sunderam S KD, Crawford SB, et al. Assisted Reproductive Technology Surveillance United States, 2014. MMWR Surveillance Summary 2017;66:1-24.

8. Martin JA, Hamilton BE, Osterman MJ, Curtin SC, Mathews TJ. Births: Final Data for 2013. Natl Vital Stat Rep 2015;64:1-65 
9. Hipp H, Crawford S, Kawwass JF, Boulet SL, Grainger DA, Kissin DM, Jamieson D. National trends and outcomes of autologous in vitro fertilization cycles among women ages 40 years and older. J Assist Reprod Gen 2017;34:885-894.

10. De Brucker M, Tournaye H, Haentjens, P, Verheyen G, Collins J, Camus M. Assisted reproduction counseling in women aged 40 and above: a cohort study. J Assist Reprod Gen 2013;30:1431-1438.

11. Schmidt L, Sobotka T, Bentzen JG, Nyboe Andersen A, ESHRE Reproduction and Society Task Force. Demographic and medical consequences of the postponement of parenthood. Hum Reprod Update 2011;18:29-43.

12. Sheinis M, Carpe N, Gold S, Selk A. Ignorance is bliss: Women's knowledge regarding age-related pregnancy risks. J Obstet Gynaecol 2018;38:344-351.

13. Wojcieszek AM, Thompson R. Conceiving of change: a brief intervention increases young adults' knowledge of fertility and the effectiveness of in vitro fertilization. Fertil Steril 2013;100:523-529.

14. Gray E, Evans A, Reimondos A. Childbearing desires of childless men and women: When are goals adjusted? Adv Life Course Res 2013;18:141-149.

15. Edge BW. Infertility on E!: Assisted reproductive technologies and reality television. Feminist Media Studies 2014;14:873-876.

16. Knobloch-Westerwick S, Willis LE, Kennard AR. Media impacts on women's fertility desires: A prolonged exposure experiment. J Health Commun 2016;21:647-657. 